\title{
IMAGINAÇÃO E LITERATURA: O CASO DE O PARAÍSO PERDIDO
}

\author{
Luiz Fernando Ferreira Sá \\ saluiz@terra.com.br
}

O paraíso perdido começa com inícios: "Diga de início, pois o Céu não esconde nada da tua vista, / Nem o profundo trato do Inferno, diga, primeiro, a causa"; 1 John Milton convoca a Musa e invoca seus predecessores, Homero, Hesíodo, Virgílio e Ovídio, os quais também estabelecem inícios e perguntam sobre as causas propiciadoras do universo criado. O paraíso perdido não se esconde por trás da pretensão de ser uma música de origem - até mesmo na sua primeira linha, o poema épico aponta, de forma implícita, a origem retroativa do erro e seus males. Deste modo, o poema épico clama pela prática ritual da repetição e lembrança da criação, uma vez que o poeta toma por obrigação a tarefa difícil de entoar uma canção que significa imaginar todo o mito de origens, de alguma forma, e todo o início das coisas é invocado novamente para explicitar, por meio da memória, a situação terapêutica da criação. A seguir, discutirei a constituição de um paraíso não artificial, seus esquemas estruturais de interioridade ou interiorização e suas formas rebeldes - origens, criatividade, releituras e imaginação crítica - como possível meio de aproximação do poema de Milton às teorias pós-coloniais, mais especificamente à obra de Edward Said.

1 Original: Say first, for Heaven hides nothing from thy view, / Nor the deep tract of Hell, say first what cause. As referências ao poema de John Milton serão seguidas de parêntesis com número do livro, ponto e número da(s) linha(s). (1. 27, 28) 
Que uma ambivalência é necessária à experiência e imaginação crítica de leitura, isto está dentro do escopo do longo poema épico. A apresentação das origens no poema não deixa de ser descomplicada: $O$ paraíso perdido é simultaneamente um cosmos alternativo, talvez uma utopia criada pelo poeta, e um mundo consciente da impossibilidade de utopias, uma vez que o paraíso foi perdido e sua restauração simplesmente está fora de alcance. Ainda assim, isto implica uma tensão que fará com que seu status de poema inaugural de uma imaginação libertadora se torne explicitamente problemático: as ocorrências da ideia de paraíso no poema ficam em um passado e sagrado tempo das origens, apontam a todo momento a impossibilidade de um original. O poema épico de Milton pode ser chamado de heterocosmo, visto que sua concepção de uma utopia ficcional ou "realidade" distópica se baseia na falta e na perda - não há possibilidade de restauração, não há nenhum lugar onde possa haver tal restauração, não há o que restaurar.

"O jardim pode ter sido destruído, bem como perdido, mas se ele existe, está no final de uma viagem de modo que não só é encontrado, mas, como diz Milton, [...] reconstituído pelo esforço de autocriação. Mais uma vez é o velho poeta cujo trabalho fornece um paradigma para a viagem e um padrão para a restauração do jardim" (RAJAN, 1978, p. 120). ${ }^{2}$ Esta imaginação de uma perda e, concomitantemente, de uma viagem geratriz, uma relativa impossibilidade de restaurar origens utópicas ou jardins perdidos, estão por sua vez associadas a outro discurso de poder: Milton sugere no poema que inícios são para serem vistos retrospectivamente, que eles esperam pelo momento de serem recriados (reconstituídos) pela memória (repetição e rememoração) e pela imaginação, pois a escolha narrativa mais "original" será aquela efetivada "com passos errantes e lentos" em direção a um "lugar de descanso" e realizada de "maneira solitária” (12: 648, 647, 649).3 Mas é Milton, de uma maneira mais imaginativa do que qualquer outro autor, que é o poeta da imaginação temporal, com sua sucessão de finais tranquilos calibrando mais uma vez, e ainda mais uma vez, a interação entre o já conhecido e o que poderia ter

\footnotetext{
2 Original: The garden may be destroyed as well as lost, but if it exists it stands at the end of a journey so that it is not only found but, as Milton puts it, [...] reconstituted by the selfadvancing effort. Once again it is the elder poet whose work provides a paradigm for the journey and a pattern for the garden's restoration.

3 Original: with wandering steps and slow / place of rest / solitary way.
} 
acontecido temporalmente, entre a criatividade do momento iluminado e sua presença permanente na imaginação de vida. O verdadeiro desafio no poema não é dizer-nos o que aconteceu (o que todos nós já sabemos) ou justificar as suas causas (o que Milton faz de forma mais complexa do que outros escritores), mas estimular-nos e libertar-nos de nossa presciência e nos ajudar a imaginar outras possibilidades. Ambivalente e serpentino como possa parecer, o paraíso não está fora, não está nem mesmo localizado numa geografia terrestre; o paraíso está dentro do surpreendente e oscilante, distraído e firme, laborioso e descansado, solitário e ocupado corpo de conscientização - um solo significante.

Ainda assim, não podemos apresentar interpretações conclusivas, pois o meu objetivo é registrar o processo de leitura do poema épico e o produto de tal registro de leitura deverá sustentar um conhecimento protelado dos inícios criados em O paraíso perdido. Ainda na esteira do pensamento de Balachandra Rajan sobre o poema épico,

O processo divino nunca se repete e a ordem por vir não pode ser inteiramente a ordem que fora destruída. Mas o corpo pode trabalhar até o espírito, tanto no nível individual quanto no possível movimento da história. O homem se encontra onde ele estava e sabe que a rede o define. Envolvimento, dependência e relacionamento não são para ele limitações, mas o contorno de sua natureza que a ação correta deve preencher e tornar perfeita. Responsabilidade é o preço da liberdade; mas também é o meio pelo qual a liberdade encontra si mesma. (RAJAN, 1970, p. 78) ${ }^{4}$

Nós sabemos agora da impossibilidade de recuperar origens, seja teoricamente, pela crítica de Jacques Derrida à procura da origem da língua empreendida por Rousseau, em Gramatologia, seja mais especificamente, pela demonstração, de acordo com Regina Schwartz (1988), de que nada em Milton é dito pela primeira vez. Schwartz procurou mostrar quantos inícios tem $O$ paraíso perdido e argumentou que Milton parece ser consciente daquela (im)possibilidade derridiana, ou seja, de que o poder de apontar e invocar do signo sempre contém o conhecimento

\footnotetext{
4 Original: the divine process never quite repeats itself and the order to come may not be entirely the order that was destroyed. But body can work up to spirit both in the individual and in the possible movement of history. Man stands where he stood and knows that the web defines him. Involvement, dependence and relationship are for him not limitations but the outline of his nature which right action must fill in and make perfect. Responsibility is the price of freedom; but it is also the means by which freedom finds itself.
} 
de que o mundo apontado e invocado por ele já se foi. O processo divino ou cadeia de significação é uma repetição com diferença, pois o solo significante do corpo de luta pode vir a ser um corpo de conscientização e, em um cenário de envolvimento, dependência e relações, é na responsabilidade do conhecimento do conteúdo esvaído, apontado e invocado pelo signo, que nasce a liberdade de escolha de um mundo alternativo. Proponho, portanto, que o poder imaginativo de $O$ paraíso perdido se encontra na tensão que o texto provoca em nós, leitores, na experiência entre a rememoração de origens, que são mais criadas do que descobertas, e na repetição de origens, que nos deve levar, necessariamente, a uma perspectiva de recriação.

No momento em que recriações foram chamadas à cena crítica, o poema épico de Milton, na medida em que é encantamento (ou seja, canta a criação e ao cantar recria a criação), é também uma distopia de encantamento. Os reinos celestes do poema estão corrompidos pela guerra e pela disputa, seu paraíso terrestre tem o sabor de fracasso e impossibilidade, e o centro do poema nada mais é que uma questão e uma procura: onde se encontra e quem é, realmente, o adversário. De forma geral, a prospecção narrativa acontece, caracteristicamente, como uma pergunta miltoniana de abertura: "E se", pergunta o narrador épico "a terra / for tão somente sombra do céu, e as coisas nela / Cada uma similar à outra, mais do que na terra se imagina?” (5: 564-576). Serão elas mais ou menos parecidas? Não há resposta. O que emerge, na maneira de um paradoxo e de uma forma serpentina, é que o Céu não é um paraíso, que o Éden pode, apesar de tudo, ser como o Céu, e que esses dois cosmos são também imaginados na Terra, em outras palavras, são criações do Homem. A criação do poeta é um heterocosmo: um cosmos alternativo, um mundo criado para e pelo homem. O heterocosmo tornou possível a concepção de utopias simultaneamente ficcionais e reais. Se o jardim terrestre paradisíaco não é a imitação da natureza a partir da mente de um poeta, mas, em vez disso, sua própria invenção, então logicamente conclui-se que os seres humanos podem realizar de forma independente as qualidades agradáveis do paraíso terrestre. Ao aproximar a teoria do heterocosmo à sociedade em geral, a imaginação utópica tentou criar uma condição humana que nada deve aos poderes

5 Original: what if earth / Be but the shadow of heaven, and things therein / Each to other like, more than on earth is thought? 
externos à razão e vontade humanas. Mas isso é exatamente o que Milton não fez. Um sistema de criação humana, como o poema épico de Milton, apropriou-se da abundância e da pseudo-harmonia do jardim e deslocou inocência para a origem. Uma inocência que não é resistência prenuncia as complicações vindouras.

Outra maneira de entender esse deslocamento é retomar a etimologia da palavra sin. Skeat (1909, p. 563) mostrou a familiaridade da palavra nas línguas germânicas com o latim sons, com o grego eson que remete novamente ao latim sunt, então carregando a ideia de ser; ser ou estar em inglês iguala-se a to be sinful, ou seja, ser ou estar em relação ao pecado. Poderíamos experienciar esse paradoxo, entretanto, somente ao construirmos uma quimera, um mundo imaginário onde to be e to be sinful são diferentes, onde o paraíso não foi ainda perdido. Ao escavarmos o texto de Milton, encontraremos os mesmos paradoxos, a mesma dobra: cada parte de texto descoberta contém o seu oposto, um texto que contradiz e aponta uma anterioridade, para além dele mesmo em um deferimento de significação ao mesmo tempo para trás e para frente. No entanto, "quanto mais se investir em mundos artificiais, mais os nossos valores serão definidos pelo poder" (BEN-TOV, 1995, p. 57) e então a dobradura ou duplicidade do poema épico da "não-origem" de Milton joga tanto com a utopia quanto com a distopia, ser e ser outro que si mesmo. Assim, uma política, digamos, pós-colonial ou imaginativamente fértil, de leitura do poema, escaparia às visões críticas reducionistas da relação ou-um-ou-outro e ofereceria ou demandaria leitura como quimera:

\footnotetext{
Manter um distanciamento na política de leitura é descobrir um Milton que não é nem imperialista nem anti-imperialista, nem uma figura ambivalente e intermediária claudicando de forma hesitante ao longo de uma estrada predeterminada. Milton funciona dentro de um discurso que é teologicamente secessionista e ainda secularmente imperial, que deve andar em uma corda bamba entre a dissidência e a obediência, discurso desgastado lentamente por suas próprias tensões internas. [...] Somos educados não só pelo que o discurso faz, mas pelo que ele não pode fazer ou não pode ver como necessário de ser feito. [...] Milton especializa-se nessas bivalências. Ele é a principal
}

6 Original: the more we invest in artificial worlds, the more our values are defined by power. Uma vez que os mundos artificiais são construídos de forma a escalonar as condições que os tornaram possíveis, os valores associados à experiência humana para além do uso do poder, como o amor ou a surpresa, se tornam cada vez menos disponíveis, ou seja, se encontram cada vez mais em "baixos" escalões. 
voz na articulação do discurso imperial e também a principal voz em seu desmantelamento. (RAJAN, 1998, p. 88)

Relações de poder simplesmente limitam o texto de Milton da mesma forma que julgamentos de valor não existem na, e ainda assim retornam à, voz do poeta. De novo, estamos lidando com as especificidades de leitura: língua, imaginação épica, logos e desmantelamento.

A narrativa de Milton sobre origens ou impérios provoca em nós um desejo de explorar essas origens e impérios por nós mesmos, e aí repetir como críticos ou leitores bem-informados, a experiência de origem e de leitura oferecida pelo poema. Em Origin and Authority in Seventeenth-Century England, Alvin Snider explora a construção, reprodução e disseminação do discurso de origem no século dezessete inglês, argumentando que "o desejo de estabelecer a legitimidade do presente por meio da recuperação e representação das origens figurou proeminentemente na escrita filosófica e na poesia épica." (1994, p.3). ${ }^{8}$ Tanto filosofia quanto poesia épica compartilham um desejo por conhecimento originário como uma alternativa ao erro. Na estimativa de Snider, Milton, mais especificamente, procura se assegurar contra o erro na viagem empreendida por "conhecimento certeiro" ao voltar-se em direção a uma "autoridade de validação de absolutos metafísicos identificada com uma origem oculta ou recuperada" (1994, p. 3). ${ }^{9}$ De certa forma, o uso miltoniano da procura épica para descobrir origens históricas e espirituais pode ser comparado à procura científica baconiana por conhecimento, e como tal, $O$ paraíso perdido é "informado pelas contradições de origem, a relação problemática entre uma cópia e seu original.” (SNIDER, 1994,

\footnotetext{
7 Original: to take the politics of reading any distance is to discover a Milton who is neither imperialist, nor anti-imperialist, nor an intermediate, ambivalent figure stumbling falteringly along an overdetermined road. Milton works within a discourse that is theologically secessionist yet secularly imperial, that must walk a tightrope between dissent and obedience frayed slowly by its own internal stresses. [...] We are educated not only by what it does but by what it cannot do or cannot see as needing to be done. [...] Milton specializes in these bivalences. He is a principal voice in the articulation of imperial discourse and also a principal voice in its dismantling.

8 Original: a desire to establish the legitimacy of the present through the recovery and representation of origins figured prominently in the writing of both philosophy and epic poetry.

9 Original: certain knowledge / validating authority of metaphysical absolutes identified with a concealed or reclaimed origin.
} 
p. 92)..$^{10}$ De acordo com Snider, Milton procura preservar a integridade das origens como absolutos transcendentes no poema épico, até mesmo quando o poeta dá conta da dificuldade de localizar uma verdade absoluta fora da linguagem. Esse dar conta é uma parte profunda e uma parcela grande do texto; verdades absolutas não podem ser localizadas em nenhum reino paradisíaco, nem podem ser encontradas em nenhuma rede de experiência humana. Origens e verdades absolutas são, usando uma das metáforas caras a Milton e finais no poema, como meteoros deslizantes que se "dobram junto ao calcanhar do trabalhador / Retornando para casa” (12:631-32)." Como Adão e Eva anteriormente, estamos fadados a trabalhar o livro do paraíso.

Caso essa última metáfora pegue o leitor na sua procura, "olhando para trás, todo o lado oriental observou / Do Paraíso," (12: 641-42) 12 e o ajude no seu ato de leitura, então colocamo-nos lado a lado de Milton no seu jogo de significação e interpretação da tradição da origem. Em relação à tradição e à imaginação crítica, Allegorical Poetics and the Epic: The Renaissance Tradition to Paradise Lost de Mindele Anne Treip é um volume da crítica miltoniana escrito com a convicção de que $O$ paraíso perdido deve ser considerado em relação à tradição crítica na qual ele cresceu (1994, p. 128). Treip empreende a tarefa de mapear uma tradição poética e exegética da alegoria estendendo-se de Aristóteles a Milton e relata essas práticas históricas junto a $O$ paraíso perdido de forma a fazer com que a alegoria venha a emergir como chave de compreensão do texto. Central no argumento de Treip é uma visão Seiscentista da formulação da alegoria como metafora continuata, uma alegoria que concede ao poeta que trabalha tal modelo uma maior flexibilidade de expressão imaginativa do que é permitido por intérpretes que enfatizam ora o aspecto figurativo ora o aspecto literal da alegoria.

Dada a sua preocupação em advertir o leitor contra estratégias reducionistas, é curioso que Treip não ache necessário questionar se a sua submissão à formulação de Tasso de um modelo binário de alegoria como uma chave interpretativa em $O$ paraíso perdido pode também ser considerada reducionista. A coerência estética que tal formulação traz

1o Original: informed by the contradictions of origins, the problematic relation between a copy and its original.

11 Original: round fast at the laborer's heel / Homeward returning. 12 Original: looking back, all the eastern side beheld / Of Paradise. 
ao poema épico, independente de sua validade histórica, impõe ordem às potencialidades generativas do texto e, necessariamente, põe limites em sua interpretação. No entanto, "Milton não pode ser concebido simplesmente como um poeta renascentista escrevendo uma metáfora escura e contínua, mas como um poeta barroco, no sentido de Benjamin, que está totalmente ciente de como a alegoria se contempla como

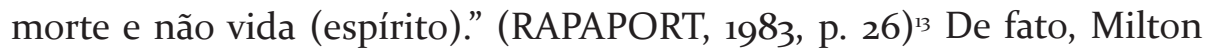
convida o leitor a desmantelar os contornos de uma alegoria estática no momento em que ele sugere, por meio do Pecado (Sin, filha de Satã), que o que Satã observa não é uma parte de uma totalidade autocontida, mas simplesmente uma repetição de algo que não significa, de forma latente, dentro da alegoria (ou seja, uma verdade diferente da alegoria ou escondida nela), uma repetição da maquinaria do engano, a alegoria em termos de uma cena de origem anterior que é tão somente a repetição de uma cena de origem anterior àquela.

O que é importante reconhecer é que é esta mecânica de repetição, da máquina alegórica, que permite que Satã e o leitor façam sentido alegórico da [narrativa], e não de qualquer significado transcendental, nem de quaisquer logos ou verdades ocultas. [...] Agora essa visão da imagem [narrativa] e da alegoria, em geral, no livro 2, contradiz a suposição habitual de que uma alegoria deve finalmente ter um significado transcendental, algo que isto aponta, pois Milton se opõe a um significado final [terminal], a uma "máquina de replicação," à "máquina literária", como Deleuze diria, cujo significado é o seu processo, o seu modo de produtividade literária. (RAPAPORT, 1983, pp. 30-31) ${ }^{14}$

Mas se a significação se encontra no processo de leitura do poema, a produção de significação literária do texto não tem sido sempre assim. O problema das origens, sua autenticação e sua leitura são aqui agudos:

13 Original: Milton can be conceived of as not simply a Renaissance poet writing a continuous dark conceit but as a baroque poet in Benjamin's sense who is fully aware of how allegory contemplates itself as death and not as life (spirit).

14 Original: What is important to recognize is that it is this mechanics of repetition, of the allegorical machine, that allows Satan and the reader to make allegorical sense out of [the narrative], not any transcendental signified, not any hidden logos or truth. [...] Now this view of the [narrational] picture and of the allegory in general in book 2 contradicts the usual assumption that an allegory must ultimately have a transcendental meaning, a thing that it points to, for Milton opposes to a terminal meaning, a "machine of replication," a "literary machine," as Deleuze would have it, whose meaning is its process, its mode of literary productivity. 
tudo isto dá lugar a uma problemática geratriz de várias respostas que não dependem de uma autoridade externa.

A título de resposta e a exemplo do que venho discutindo, uma profunda gratidão pela obra de Milton informa uma das primeiras visões críticas de $O$ paraíso perdido: "O leitor declarou que ele 'nunca antes lera qualquer coisa mais sublime, e acima de tudo mais adequada à minha (muito limitada) compreensão.' Isto parte do presbiteriano Sir John Hobart (1628-1683), que aplaudiu O paraíso perdido em duas cartas a seu primoem janeirode1667/8." (MALTZAHN, 1996, p. 490). ${ }^{15}$ O presbiteriano conservador, Sir John Hobart, dá as boas vindas ao tour de force cristão miltoniano como um contrapeso à cultura irreligiosa da corte de Carlos II da Inglaterra. Outro exemplo: "o registro mais completo do conflito entre a má reputação política de Milton e as novas reivindicações de seu épico religioso aparece nas cartas de John Beale a John Evelyn. Até que ponto a dissidência está relacionada à sedição?" (MALTZAHN, 1996, p. 494). ${ }^{16}$ Tolerância para Beale permanece uma ameaça, e ele parece gritar ainda mais alto por controle e uniformidade: o exemplo que ele cita é o final de $O$ paraíso perdido, o republicanismo escancarado da passagem no décimo segundo livro do longo poema sobre Nimrod: "Tudo isso exemplifica o que Beale se refere a como o 'velho princípio' de Milton: o poema descreve a tirania na história e é abertamente antimonárquico, $\mathrm{e}$ a súplica de Milton em favor do 'nosso direito Original', como Beale se refere a isso em outro lugar, é uma das 'grandes falhas em seu Paraíso Perdido”' (MALTZAHN, 1996, p. 497). ${ }^{17}$ Apesar do que Beale e Hobart viram como republicanismo em $O$ paraíso perdido, com suas respostas desordenadas, eles foram sensíveis às inspirações do poeta e "à sua visão severa sobre a nação ou o indivíduo impérvio à reforma [... Beale] não gostava nada da demonologia assustadora do épico, e ele a via como

15 Original: the reader professed that he 'never read any thing more august, \& withall more gratefull to my (too much limited) understanding'. This is from the Presbyterian Sir John Hobart (1628-83), who applauded Paradise Lost in two letters to his cousin in January $1667 / 8$.

16 Original: the fullest record of the conflict between Milton's bad political reputation and the new claims of his religious epic appears in the letters of John Beale to John Evelyn. How far should Dissent be linked with sedition?

17 Original: All this exemplifies what Beale terms Milton's 'old Principle': the poem's description of tyranny in history is openly anti-monarchical, and Milton's 'Plea for our Original right', as Beale terms it elsewhere, is one of the 'great faults in his Paradyse Lost. 
decorrente de uma imaginação punitiva, calvinista e persecutória” (MALTZAHN, 1996, p. 497).18 Esta imaginação persecutória parece assombrar a leitura daqueles que procuram em $O$ paraíso perdido respostas fáceis a um dos inícios do poema: "Da primeira desobediência do homem, e o fruto / Daquela árvore proibida” (1. 1,2). ${ }^{19}$ Em Milton, a resposta de leitura, de forma recompensadora e encontrada no próprio poema, está na conversação com as inexplicáveis mudanças na estrutura de poder.

Tal conversação, quase uma conversão de leitura, algumas vezes ocasionada por inversão, outras vezes por adaptação maliciosa, Milton parece demandar de sua audiência quando ele faz com que narrativas diametricamente opostas se tornem "assustadoramente" tensionadas nas suas versões dos superpostos mitos de explanação da tradição cristã e pagã de que ele fez uso para estender a narrativa de seu poema. Mary Jo Kietzman em "The Fall into Conversation with Eve: Discursive Difference in Paradise Lost”, por exemplo, lê a queda como não existente, porque o Jardim do Éden de Milton não é um lugar de onde se cai ou um estado de inocência a se perder, mas um experimento social - a possibilidade de criação de uma, digamos, conversação adequada e feliz (1997, p. 55). Portanto, a experiência da queda é nada mais que uma falta na conversação humana e, talvez, uma falta ou fracasso de leitura do texto divino.

Essa segunda falta pode ser situada na leitura e descrição pertinente de Dayton Haskin do paraíso de Milton: o paraíso do poeta pode ser visto como uma condição de possibilidade para trabalhos de interpretação significativos (1994, p. 220) - um supertexto que Adão e Eva devem ler e interpretar do mesmo modo que os cavaleiros de Spenser leram sobre as escapadelas de duendes e fadas da terra pastoral seiscentista inglesa. O labor interpretativo de Adão e Eva no paraíso de Milton pode então ser atualizado no decreto divino de que eles se façam autores deles mesmos: "autores para si em tudo / Tanto no que eles julgam quanto no que eles escolhem" (3: 122-3). ${ }^{20}$ Autores para eles mesmos é bastante

18 Original: to his stern view on the unreforming individual or nation [... the former] much disliked the fearful demonology of the epic, which he saw as deriving from a punitive, Calvinist, persecutory imagination.

19 Original: Of Man's first disobedience, and the fruit / Of that forbidden tree.

20 Original: authors to themselves in all / Both what they judge and what they choose. 
diferente da "desleitura" ${ }^{21}$ satânica de autocriação ou engendramento de si, pois Milton cria um paraíso onde falha e falta de reconhecimento e de exploração da interioridade são um ponto chave para entender a queda. As cenas pedagógico-históricas finais, nas quais Miguel relata o porvir ao atento Adão e à sonolenta Eva,

Estão muito alinhadas à análise de Jacques Derrida do signo como um traço em De la grammatologie, quando Derrida diz que o traço pertence a uma "économie de la mort" e que o grau de deriva em direção à morte, em direção à perda do sujeito, em direção a um desvanecimento da consciência e um apagamento da presença determina até que ponto o sujeito vai ressuscitar os vestígios daquela forma longe da qual o sujeito se encontra a cair. (RAPAPORT, 1983, p. 45) ${ }^{22}$

Miguel tenta convencer Adão e Eva de que o sujeito sofre, não porque ele está sendo cruelmente punido, mas porque ele voluntariamente se rebaixa e lê o texto satânico de conhecimento e conquista. O poema épico de Milton, quase que ironicamente conversando com o texto divino, parece conceder poder àqueles que se aventuram na interioridade de seu texto.

Milton ocupou, para os revolucionários do século dezoito e na América do Norte, um lugar de destaque no topo de uma lista de escritores cuja obra constituía uma verdadeira herança ideológica e cujo intento era adentrar a interioridade de seu texto. O poema prospectivo de Milton, O paraíso perdido, "não é uma revelação da bem-aventurança a ser discernida a partir do 'topo mais justo do Pisga"' (STAVELY, 1990, p. 154), ${ }^{23}$ nem mesmo se constitui como a beleza e os benefícios dispensados às províncias da Inglaterra e do País de Gales, num levantamento geográfico idealizado da nação eleita, mas uma revelação de uma expansiva e ampliada política

21 Faço uso do termo "desleitura" a partir de Friedrich Nietzsche, que propõe, no seu ensaio "On Truth and Lie in an Extra-Moral Sense," o seguinte paradoxo: "verdades são ficções cuja ficcionalidade foi esquecida [truths are fictions whose fictionality has been forgotten.]" Daí, a discussão acerca de leituras válidas e leituras in-válidas, no sentido de interpretação de determinado texto. Seguindo as políticas de leitura informadas pela desconstrução de Jacques Derrida e Paul de Man, Gayatri Spivak e Harold Bloom expandiram o uso do termo.

22 Original: are very much in line with Jacques Derrida's analysis of the sign as a trace in De la grammatologie, when Derrida says that the trace belongs to an "économie de la mort" and that the degree to which one drifts towards death, towards a loss of the subject, towards a fading of consciousness and an effacement of presence determines to what extent one will resuscitate traces of that form which one is falling away.

23 Original: is a revelation not of the bliss to be discerned from a 'fairer Pisgah's top'. 
de leitura constitutiva de um paraíso possivelmente onde "violência / Prossiga, e opressão, e espada da lei / Por toda a planície, e refúgio nenhum foi encontrado" (11. 671-73). ${ }^{24}$ Do Velho ao Novo Testamento, da perda do paraíso edênico à reconquista do paraíso interno, tudo parece ser desmantelado numa regressão abrangente que traduz (transporta ou transforma) poema épico em tragédia e o Novo Testamento de volta ao Velho; "por todos esses meios, Milton substancia ao máximo a sua avaliação de sua situação como tendo sido expatriado do patriotismo." (STAVELY, 1990, p. 155).25 Apesar de Milton parecer indicar a seus poucos e aptos leitores que ele não quer participar das aventuras histórico-mundanas dos povos de língua inglesa e que ele se encontra numa situação de expatriado de um certo patriotismo,

Uma série de poetas ingleses do século dezoito já tinha usado o estilo e imagens recorrentes de Milton a fim de derrubar seus significados e vislumbrar a glória crescente do Império Britânico como a reconquista do paraíso. Em outras palavras, a literatura secular tornou-se suficientemente bem definida para reproduzir em si o próprio processo pelo qual tinha sido criada: assim como signos literários gradualmente foram redirecionados de significações religiosas a significações seculares, portanto, uma forma e um estilo miltonianos estavam sendo desviados do miltoniano para o não-miltoniano de fato e para o conteúdo anti-miltoniano. (STAVELY, 1990, p. 155-156) ${ }^{26}$

O poema épico de Milton, mais especificamente, foi pego na divisão colonial: tanto coloniais o liam como veículo revolucionário quanto colonialistas o liam como visão glorificada do império britânico. Ainda assim, a persistência de tentativas violentas para subscrever Milton e seu poema épico para dentro da visão imperial anglo-americana serve de prova de como uma assimilação e reintegração desse mesmo texto às questões coloniais ou imperiais eram profundamente sentidas como necessárias.

24 Original: violence / Proceed, and oppression, and sword-law / Through all the plain, and refuge none was found.

25 Original: by all these means, Milton substantiates to the fullest his assessment of his situation as one of having been expatriated from patriotism.

26 Original: a number of 18th-century English poets had already used Milton's style and motifs in order to overturn his meanings and envision the rising glory of the British Empire as the regaining of paradise. In other words, secular literature had become well enough defined to reproduce within itself the very process by which it had been created: just as literary signs had gradually been redirected from religious to secular significations, so a Miltonic form and style was being deflected from Miltonic to non-Miltonic-indeed to anti-Miltonic-content 
O colosso da literatura de língua inglesa andava a passos largos como também o colosso da economia e marinha britânicas andava a passos largos no cenário do comércio mundial. Qual poeta poderia ocupar o ápice ou centro desse colosso tanto em forma quanto estilo? Qual política de leitura seria necessária para adaptá-lo a tal ápice ou centro? E mais: o que fazer do conteúdo miltoniano?

\begin{abstract}
Não é por acaso que Joseph Addison, um grande ideólogo do império nascente, iria formular, vinte e cinco anos depois, a visão sobre Milton que seria definitiva ao longo do século dezoito: "Como seu gênio estava maravilhosamente virado em direção ao sublime, seu tema é o mais nobre que poderia ter entrado os pensamentos do homem. Cada coisa que é verdadeiramente grande e surpreendente, tem um lugar [n'O paraíso perdido].” Addison pontuara as necessidades ideológicas que ele estava articulando quando ele terminou a sua série de ensaios sobre $O$ paraíso perdido, ao declarar que o poema "traz honra à nação inglesa." (STAVELY, 1990, p. 156) ${ }^{27}$
\end{abstract}

Uma nação-ilha que andava a passos tão largos ao redor do mundo necessitava um poeta nacional cujo gênio estivesse irremediavelmente voltado para o que há de sublime, "assim como, mais tarde, uma nova nação continental que estava a caminho de se tornar 'um império grande e poderoso; a maior que o mundo já viu', precisava adotar um poeta cuja alma, como o jovem John Adams anotou em seu diário em 1756, 'foi distendida tão amplamente como a criação.” (STAVELY, 1990, p. 157).28 As políticas de leitura associadas a Milton e a seu paraíso durante o século dezoito e durante a revolução norte-americana devem, portanto, ser adicionadas à longa lista das ironias que constituem a história literária. O século dezoito fez de Milton o que ele inicialmente havia planejado se tornar, mas que, depois de perdas e percalços pessoais e nacionais, o poeta decidiu colocar de lado.

27 Original: It is no accident that Joseph Addison, a major ideologist of nascent empire, formulated twenty-five years later the view of Milton that would be definitive throughout the 18th century: "As his Genius was wonderfully turned to the Sublime, his Subject is the noblest that could have entered into the Thoughts of Man. Every Thing that is truly great and astonishing, has a Place in it." Addison hinted at the ideological needs he was articulating when he brought his series of essays on Paradise Lost to a close by declaring that the poem "does an Honour to the English Nation."

28 Original: just as, later, a new continental nation that was on the way to becoming "a great and mighty Empire; the largest the World ever saw," needed to adopt a poet whose soul, as the youthful John Adams noted in his diary in 1756, "was distended as wide as creation." 
Após a calamidade da Restauração, Milton promove uma Inglaterra republicana que seria tão contida e restrita quanto Esparta e Veneza no sentido de uma "commonwealth" de preservação, tão virtuosa e hostil à corrupção política e econômica que não precisaria de ostentação de forma alguma. Com o fracasso desse último refúgio nacional para os seus ideais republicanos e cristãos,

Milton está preparado, depois da Restauração, para renunciar completamente a sua fidelidade à nação Britânica constituída de eleitos. Em uma carta escrita em 1666 e publicada em 1674 como a última das Cartas Familiares, Milton informa a seu correspondente que ele se sente como se o "Patriotismo [...] quase me tivesse expatriado, por assim dizer. [...] A Pátria se encontra onde o sujeito se sentir bem." (STAVELY, 1990, p. 153)

Ao clamar por um estado mental que possa substituir um tipo alternativo de estado-nação, essa postura-perspectiva que governa a maturidade poética de Milton não pode ser vista como apolítica ou paralisante. Essa pátria que pode vir a ser o paraíso interno também está no mundo - "O mundo todo estava à frente deles." (12. 646) ${ }^{30}$

O reconhecimento de limites, a renúncia à grandiosidade histórica mundial em favor da habitação humana simples e a solidariedade se apresentam como uma oportunidade não de retiro, resignação e quietismo, mas de ampla visão, esperança e ativismo. Podemos honrar o poeta o qual nossos antepassados acreditavam tê-los honrado por finalmente começar a levá-lo a sério. (STAVELY, 1990, p. 159) $)^{31}$

Para sermos sérios ao ler Milton, temos de escolher ler o poema épico nas suas escolhas narrativas "originais". Desse modo, tenho podido, por exemplo, questionar as leituras (críticas) do poema que o ligam a uma visão colonialista e "desler" o texto por dentro de uma perspectiva póscolonial.

29 Original: Milton is prepared after the Restoration to renounce altogether his allegiance to the British Elect nation. In a letter written in 1666 and published in 1674 as the last of the Familiar Letters, Milton informs his correspondent that he feels as if 'Patriotism [...] has almost expatriated me, as it were. [...] One's Patria is wherever it is well with him. 3o Original: The world was all before them.

31 Original: the recognition of limits, the renunciation of world-historical grandiosity in favor of simple human habitation and solidarity is presented as an occasion not of retreat, resignation, and quietism but rather of expansive vision, hope, and activism. We can honor the poet whom our ancestors believed had done honor to them by finally beginning to take him seriously. 
A escolha narrativa mais "original” e séria no poema épico de Milton tem a ver exatamente com aquele momento, o momento das origens - "auto-autorização" -, momento este que não pode ser alcançado. Remetendo-nos às ações passadas no poema, a queda humana havia sido "prefigurada" ou "alcançada" quando Lúcifer e os anjos dissidentes se rebelaram contra a paternidade, autoria e autorização do criador todopoderoso. "Satã, cuja queda prefigura a do homem que será o homem do pecado e da morte, caiu porque ele se rebelou, e sua revolta gera, a partir do desejo orgulhoso, uma auto-perpetuação." (MOUCHARD, 1996, p. 503).32 Auto-perpetuado e engendrado, Satã se revolta contra o decreto divino, no momento que o Filho (Cristo) era exaltado e elevado a seu novo papel, consagrado e originado.

A filiação teria se tornado, em geral - no centro da transformação de todos os relacionamentos -, formidável? Pode ser esta a prova difícil que emana d'O paraíso perdido. E por isto que a modernidade literária será afetada: a transmissão ritual (heroica, agonística) da tarefa épica corre o risco, embora ainda vista como central, de se revelar impossível - ou ridícula. (MOUCHARD, 1996, p. 504) $)^{33}$

Mesmo que Milton tenha transformado a narrativa da inveja de Satã em uma narrativa da origem do mal - o momento chave desse enredo - a cena primordial do nascimento do mal é eludida, como em todas as narrações parecidas. Seria, então, como se Milton riscasse a impossibilidade da procura por um início (filial ou do mal) com um traço, traço este que demarca um nunca-chegar-lá.

É neste traço que demarca um nunca chegar lá que eu posso situar o poema épico de Milton também por dentro de um contexto pósmoderno e apreciar o poema pós-renascentista e pré-iluminista, na esteira da história literária, após minha destituição desse texto de seus traços de leituras e releituras tendenciosas, e possivelmente na esteira

32 Original: Satan, dont la chute préfigure celle de l'homme et qui sera pour l'homme cause du péché et de la mort, est tombé parce qu'il s'est révolté, et sa révolte découle du désir orgueilleux d'auto-engendrement.

33 Original: La filiation serait-elle devenue, en général-au coeur de la transformation de tous les rapports-, redoutable? C'est peut-être cette évidence difficile qui émane du Paradis Perdu. Et c'est par quoi la modernité littéraire serait affectée: la rituelle transmission (héroïque, agonistique) de la tâche épique risquerait, quoiqu'encore vue comme centrale, de s'y révéler impossible-ou dérisoire. 
da história da filosofia como a encontramos hoje, após George Bataille, Gilles Deleuze, Julia Kristeva, Roland Barthes, Michel Foucault e Jacques Derrida. Essa segunda esteira de leitura estará presente na tese que aqui desenvolvo por meio das práticas pós-coloniais de Edward Said. O ato de leitura desconstrutivo de várias séries e registros não resulta em colapso ou destruição do texto literário em si ou de sua tradição de leitura, mas em salvamento do texto. Ou seja, o que fica? O que não foi abalado? Quais são as sobras? O que é salvado (Aufgehoben, dado salvação)?

O processo de leitura que proponho, no ato mesmo de desconstrução, tem a ver com restituição: restituir a $O$ paraíso perdido o que é de $O$ paraíso perdido. Já no século dezenove inglês, temos um alerta:

Macaulay sabe que "os homens que demoliram as imagens nas catedrais não foram sempre capazes de demolir aquelas que se encontram consagradas em suas mentes", e isto é particularmente relevante para Milton, pois a sua prosa e poesia estão compromissadas com a evasão desses erros - o que significa um projeto filosófico difícil, ainda mais se pensarmos numa agenda marxista e pós- estruturalista contemporânea, de não simplesmente transcender um idealismo por meio de outro, mas de se manter de pé, de modo dialético, numa arena de debate que ao mesmo tempo engaja e desengaja os aparatos conceituais metafísicos que constituem a filosofia ocidental (o que Jacques Derrida chama de "mitologia branca"). (RAPAPORT, 1983, p. 3$)^{34}$

Vale lembrar que desconstrução não é sinônimo de destruição, subversão ou assassinato de cultura ou de história, mas refere-se à peculiar resistência e marginalidade de certos registros textuais que ocupam zonas liminais, "motivos discutíveis, ou limiares indecidíveis, registros que os leitores muitas vezes passam por cima ou conseguem forçar a um alinhamento logocêntrico." (RAPAPORT, 1983, p. 5) ${ }^{35}$

34 Original: Macaulay knows that "the men who demolished the images in cathedrals have not always been able to demolish those which were enshrined in their minds," and this is particularly relevant to Milton, for his prose tracts and poems are committed to an evasion of both these errors-what amounts to the difficult philosophical project, still on the contemporary Marxist and poststructuralist agenda, of not simply transcending one idealism by means of another but of standing dialectically on a debatable ground that at once engages and disengages the metaphysical conceptual apparatuses that constitute Western philosophy (what Jacques Derrida terms the "white mythology").

35 Original: debatable grounds, or undecidable thresholds, registers which readers often pass over or manage to force into a logocentric alignment. 
Milton não é um poeta da presença, do espírito e de ídolos, mas um iconoclasta que opõe tal orientação ao texto, especialmente em $O$ paraíso perdido. Mas meu projeto ou estratégia de leitura, uma “desleitura”, é tomar uma orientação ou perspectiva pós-colonial para facilitar a imigração desse poeta inglês do século dezessete em direção ao solo expatriado das ex-colônias do final do século vinte. Meu projeto de leitura parte da premissa de que $O$ paraíso perdido carrega consigo a segurança contra o projeto alquímico arrogante de se tornar Escritura ao expandir a Escritura; e de que $O$ paraíso perdido desconstrói ele mesmo para se assegurar de um nunca-chegar-lá - aceder à noção de Escritura sem ser Escritura.

É suposição comum que, depois da narrativa da queda, O paraíso perdido subordina a importância de um lócus externo ao paraíso psicológico e espiritual interior de escritura do corpo e no corpo. Parece-me, no entanto, que mesmo antes da narrativa da criação em si, o poema épico provê um mapeamento conceitual que solapa a ideia de paraíso com a faculdade imaginativa controlada e subversiva do poeta.

Milton escapa das armadilhas e redes do fácil formalismo e historicismo inglês, porque ele não está trabalhando dentro de tradições filosóficas e metafísicas, mas tentando, como um Hegel, um Marx, um Nietzsche, fazer algo violento com essa tradição, afetá-la, com o uso estratégico de um estilo radical cuja dureza tem a finalidade de perfurar ou rasgar o discurso resistente e duro que conhecemos como metafísica ocidental e que Milton conhecia como escolástica e classicismo. (RAPAPORT, 1983, p. 21) 36 $^{6}$

A queda lega-nos a perda de um ambiente espacial contido ea inovação de um mundo que está mais atenuado porque baseado na linguagem, histórico porque dependente de contextos, e topológico porque sempre se movendo para trás e para frente atrás do definhado, desfalecido ponto de origem ou nó da metafísica ocidental.

A temática da perda objetal é muito claramente uma grande preocupação, talvez até a maior preocupação, d'O Paraíso Perdido, e não só porque $O$ paraíso perdido é um poema sobre a Queda, sobre a relutância de Adão abandonar Eva,

36 Original: Milton escapes the gins and nets of easy English formalism and historicism, because he is not working within philosophical and metaphysical traditions, but attempting, like a Hegel, a Marx, a Nietzsche, to do something violent to this tradition, to affect it, with the strategic use of a radical style whose hardness has the purpose of puncturing or tearing the resistant, tough discourse that we know as Western metaphysics and that Milton knew as scholasticism and classicism. 
sobre a expulsão de Satã do céu, sobre a desistência do homem de sua vida eterna e de sua imagem divina, mas porque a temática da perda objetal diz respeito à questão da própria linguagem. (RAPAPORT, 1983, p. 35) ${ }^{37}$

A perda da presença de Deus e a expulsão do paraíso estão para ser "recuperadas" em termos de reinvestimentos de leitura nos traços de Deus, sua Graça, o sacrifício do Filho e, finalmente (como um novo início), o paraíso interno. $\mathrm{O}$ corpo da linguagem e a leitura dessa linguagem ou língua do paraíso, como também qualquer estratégia de leitura e uso desse texto inglês hipercanônico, devem já e sempre evadir submissão à autoridade (imperial), e devem já e sempre representar a multiplicidade de espaços onde relações ambivalentes e pós-modernas de autoridade, identidade, origem e interpretação possam ser articuladas. Milton e seu texto-assinatura, $O$ paraíso perdido, intimam o intelectual, o leitor bem-informado ou crítico pós-colonial a embarcar nessa situação de criação terapêutica.

No entanto, para embarcar nessa criação terapêutica de "desleitura", uma verdadeira imaginação crítica, tenho de discutir a posição do intelectual ou crítico pós-colonial nesse mar de dificuldades. Há sempre a questão de objetivos que, mesmo no meio de um mar revolto, requer uma análise das escolhas. Estou aqui lendo O paraíso perdido no intuito de me livrar das leituras imperialistas do poema, um objetivo fundamental para críticos pós-coloniais, ou, como diria Said,

"estamos pensando no que vamos fazer quando o último policial branco sair? Segundo Fanon, o objetivo do intelectual nativo não pode ser simplesmente substituir um policial branco pelo seu homólogo nativo, mas antes o que nós chamamos, pedindo emprestado a Aimé Césaire, de invenção de novas almas." $(1994 \text {, p. 41) })^{38}$

Sem dúvida, estou tanto me livrando do crítico imperial e certamente policial do império quanto inventando uma situação terapêutica de leitura

37 Original: The thematic of object loss, of course, is only too clearly a major concern, perhaps even the major concern, of Paradise Lost, and not only because Paradise Lost is a poem about the Fall, about Adam's reluctance to abandon Eve, about Satan's expulsion from heaven, about man's forfeit of his eternal life and his divine image, but because the thematic of object loss concerns the question of language itself.

38 Original: are we thinking about what we will do when the last white policeman leaves? According to Fanon, the goal of the native intellectual cannot simply be to replace a white policeman with his native counterpart, but rather what we called, borrowing from Aimé Césaire, the invention of new souls. 
que é também uma certa "invenção de novas almas" de críticos e leitores pós-coloniais.

Se, de acordo com Said, a tarefa do intelectual ou crítico é "explicitamente universalizar a crise para dar maior alcance humano ao sofrimento de uma raça ou nação em particular, associar essa experiência aos sofrimentos dos outros." (1994, p. 44),39 tento explicitar as acusações crítico-imperiais ao poema épico de Milton para, então, lê-lo ao lado de uma situação humana maior, a situação pós-colonial. Para tanto, elenco as seguintes máximas: primeiro, levar em consideração a "acusação muitas vezes repetida de que 'as grandes narrativas de emancipação e iluminação', como o filósofo francês contemporâneo Lyotard se refere às tais ambições heroicas associadas à idade 'moderna' anterior", e aí podemos situar $O$ paraíso perdido, "são denunciadas como não tendo mais qualquer valia na era do pós-modernismo. De acordo com este ponto de vista, as grandes narrativas foram substituídas pelas situações locais e jogos de linguagem; intelectuais pós-modernos agora prezam competência, e não os valores universais como a verdade ou a liberdade." (SAID, 1994, p. 17-18).40 Faço o poema épico de Milton circular na era pós-moderna e na teoria pós-colonial ao sublinhar as situações locais do paraíso, seus jogos de linguagem e a competência para ler tal linguagem.

Segundo, "saber usar bem a língua e saber quando intervir na linguagem são duas características essenciais da ação intelectual” (SAID, 1994, p. 20). ${ }^{41}$ Ou seja, leio o poema épico menos como propaganda do império provinda das linhas de um autor genial e mais como uma intervenção intelectual de um exímio linguista e poeta.

Terceiro, uma vez que "houve mesmo uma influente escola de filósofos, entre os quais Michel Foucault é muito bem considerado, que dizem que falar de um autor (como em 'o autor dos poemas de Milton')

39 Original: explicitly to universalize the crisis, to give greater human scope to what a particular race or nation suffered, to associate that experience with the sufferings of others. 40 Original: the often repeated charge that 'grand narratives of emancipation and enlightenment,' as the contemporary French philosopher Lyotard calls such heroic ambitions associated with the previous 'modern' age are pronounced as no longer having any currency in the era of postmodernism. According to this view grand narratives have been replaced by local situations and language games; postmodern intellectuals now prize competence, not universal values like truth or freedom.

41 Original: knowing how to use language well and knowing when to intervene in language are two essential features of intellectual action. 
é altamente tendencioso, para não dizer ideológico, exagerado," (SAID, 1994, p. 91 $)^{42}$ prefiro tratar do texto e deixar o autor de lado.

Quarto,

Certamente na escrita e na fala, o objetivo do sujeito não é mostrar a todos quão certo o sujeito está, mas antes tentar induzir uma mudança no clima moral em que a agressão é vista como tal, a punição injusta de povos ou indivíduos ou é impedida ou é deixada de lado, o reconhecimento dos direitos e liberdades democráticas é estabelecido como norma para todos, e não injustamente para um grupo seleto. (SAID, 1994, p. 100) ${ }^{43}$

Se O paraíso perdido tinha um "grupo seleto" como público leitor, talvez os intelectuais ingleses e europeus da época, pretendo abrir o leque de opções em direção aos povos pós-coloniais ao demonstrar que o poema não mostra quão certo ele está na sua plataforma política, e, antes de tudo, defende e induz a uma mudança ética em termos de direitos e liberdades (até então só republicanas para o nosso autor). E mais, falar a "verdade" do poema épico de Milton foi e é, naquela sociedade de censores e na nossa de administradores da massa, projetar/deferir um estado de coisas que corresponda a um conjunto de princípios éticos: paz, reconciliação, diminuição do sofrimento.

Quinto,

O intelectual ao longo do tempo se volta naturalmente em direção ao mundo da política, em parte porque, ao contrário da academia ou do laboratório, aquele mundo é animado por considerações, de poder e interesse, escritas em forma de Escritura e que conduzem toda uma sociedade ou nação, o que, como Marx disse de modo fatídico, leva o intelectual de perguntas relativamente discretas sobre a interpretação às muito mais significativas sobre mudança e transformação social. (SAID, 1994, p. 109-110) ${ }^{44}$

42 Original: there has even been an influential school of philosophers, among whom Michel Foucault ranks very high, who say that to speak of an author at all (as in 'the author of Milton's poems') is a highly tendentious, not to say ideological, overstatement.

43 Original: certainly in writing and speaking, one's aim is not to show everyone how right one is but rather to try to induce a change in the moral climate whereby aggression is seen as such, the unjust punishment of peoples or individuals is either prevented or given up, the recognition of rights and democratic freedoms is established as a norm for everyone, not invidiously for a select few.

44 Original: the intellectual over time naturally turns towards the political world partly because, unlike the academy or the laboratory, that world is animated by considerations of power and interest writ large that drive a whole society or nation, that, as Marx so fatefully said, take the intellectual from relatively discrete questions of interpretation to much more significant ones of social change and transformation. 
O poema épico de Milton deve ser lido menos como uma ou mais interpretações da sua sociedade e nação e mais como uma ação de um intelectual em direção a mudanças (social, de ponto de vista) e transformações (tradição, gênero literário).

Com todos esses pontos em vista, não pretendo aqui proclamar, como em relâmpagos e raios de um Velho Testamento, a "verdade" pós-colonial "absoluta" do poema épico de Milton. Pretendo sugerir algo muito mais modesto e talvez mais efetivo. O texto de Milton, ao falar de um paraíso interno e de sua possibilidade - "[o que] nãoéolhar para dentroà procura de uma luz guia fornecida ao sujeito por inspiração ou intuição profética” -, é político e conclama a uma ação política, e agora também ação pós-colonial, mas num cenário pessoal ético delicado, sem o estardalhaço daqueles que falam em cima de plataformas políticas ou em auditórios acadêmicos "de consistência na defesa das normas de conduta internacional e dos direitos humanos." (SAID, 1994, p. 97).45 Este percurso crítico que perfiz aponta a postura de Milton com relação à sua criatividade, a qual se caracteriza por uma consciência histórica e uma visão (des)ordenadora do universo, aponta a imaginação crítica de um poeta cujo poema remata os fins passados e os inícios futuros numa conclusão aberta às responsabilidades que acompanham todo destino e toda herança e, finalmente, aponta um remate de males: a parte combativa de sua estética, a sua reflexão ética, últimas operações destinadas a tornar imaginativamente sublime uma obra nesses inícios da modernidade inglesa.

\section{REFERÊNCIAS BIBLIOGRÁFICAS}

BEN-TOV, Sharona. The artificial paradise: science fiction and American reality. Ann Arbor: The University of Michigan Press, 1995.

HASKIN, Dayton. Milton's burden of interpretation. Filadélfia: University of Pennsylvania Press, 1994 .

KIETZMAN, Mary Jo. The fall into conversation with Eve: discursive difference in Paradise Lost. Criticism. Michigan: Wayne State University Press, v. 39, n. 1, 1997.

45 Original: [which] is not to look inwards for a guiding light supplied to one by inspiration or prophetic intuition / of consistency in upholding standards of international behavior and the support of human rights. 
MALTZAHN, Nicholas. The first reception of Paradise Lost (1667). The Review of English Studies. Oxford: Oxford University Press, v. 47, n. 188, 1996.

MILTON, John. John Milton: complete poems and major prose. HUGHES, Merrit Y. (Ed.). New York: Hackett Publishing, 1957.

MOUCHARD, Claude. Chateaubriand, Milton, l'épopée et la prose. Revue de Littérature Comparée. Paris: Édouard Champion, v.4, 1996.

RAJAN, Balachandra. The lofty rhyme. Coral Gables: University of Miami Press, 1970.

RAJAN, Balachandra. Milton and Eliot: a twentieth-century acknowledgement. Milton Studies. Pittsburgh: Duquesne University Press, v. 11, 1978.

RAJAN, Balachandra. Milton encompassed. Milton Quarterly. Nova York: Wiley, v. 32, n. 3, 1998.

RAPAPORT, Herman. Milton and the postmodern. Lincoln: University of Nebraska Press, 1983.

SAID, Edward. Representations of the intellectual. Londres: Vintage, 1994.

SCHWARTZ, Regina. Remembering and repeating biblical creation in Paradise Lost. Cambridge: Cambridge University Press, 1988.

SKEAT, Walter W. An etymological dictionary of the English language. Oxford: Clarendon Press, 1909.

SNIDER, Alvin. Origin and authority in $17^{\text {th }}$-century England: Bacon, Milton, Butler. Toronto: Toronto University Press, 1994.

STAVELY, Keith W. F. The world all before them: Milton and the rising glory of America. In: Studies in $18^{\text {th }}$-century Culture. East Lansing: Colleagues Press, 1990.

TREIP, Mindele Anne. Allegorical poetics and the epic: the renaissance tradition in Paradise Lost. Lexington: Kentucky University Press, 1994. 